9. It is true, as Mr. Pratt states, that Senate bill 1063 was reported unanimously by the Committee on the District of Columbia. I believe that I am correct in stating that this matter was left by his colleagues on the Committee very largely in the hands of Senator Gallinger, who would seem from his report on the bill to be an extreme antivivisectionist. He must by this time realize that in this matter he has antagonized the sentiments of the great majority of medical and scientific men of this country. There never was an adequate presentation of the arguments against the bill bafore the Committee. I have information that at least some members of the Committee have changed their opinions and are now opposed to the bill.

10. It is likewise true that a very impressive list of names is attached to a petition favoring this legislation. Here again I know of some who, having become better informed, have written letters retracting their consent. You know better than I how much value is to be attached in general to such petitions, for which it is sufficiently easy to secure signatures. Undoubtedly not a few of the general public have been misled by the grossly false, misleading and sentimental appeals of antivivisectionists. Upon this matter it is the voice of science and of medicine, which is likewise the voice of true philanthropy, which should be heard and which should control legislative action, and not that of those who, however worthy their im. pulses, however high their social position, however great their knowledge in other departments, do not possess that special knowledge which renders them competent to judge of the merits of this question. The voice of science and of medicine, so far as it receives authoritative utterance, is overwhelmingly opposed to any such legislation as that contemplated by this bill.

As to the necessity and great value of animal experimentation to ecientific and practical medicine, both human and veterinary, and to biological science, there is practically no difference of opinion among well informed medical and scientific men. Thousands of lives of both human beings and animals have been saved and in increasing number will lives continue to be saved by knowledge which could have been gained only through experiments on animals.

In conclusion permit me to express my gratification, and I may safely add the gratitude of all enlightened physicians and scientists, that your powerful influence is being exerted in opposition to the enactment of Senate bill 1063. In this you have espoused the cause not only of science but also of humanity.

\section{Malaria Infection.}

Charlotte, N. C., March 7, 1898.

To the Editor:-In your remarks under the above heading, in the issue of March 5, 1898 (page 561), you make some statements which appear to deserve some qualification, at least from $m y$ information and experience on the subject. That there is a form of malaria (the disease) which resists the therapeutic action of quinin even when in proper dosage by the stomach, rectum and skin, is within the experience of a number of phy sicians throughout the South. This form of malaria, designated the estivo-autumnal, will not infrequently persist in spite of the exhibition of large and repeated doses of quinin, the pa. tient dying literally saturated with the drug and thoroughly cinchonized. Dr. Osler, the highly gifted and capable authority quoted to support the points of the editorial, has given absolute testimony to the fact that quinin will not remove the crescentic forms from the blood and that the fever will persist in spite of its use. Writing to me in answer to a communication, he replies to the question as to whether in his experience there was a form of malarial fever that resisted quinin: "Yes, the estivo-autumnal resists in certain phases. The organismcrescents - do not disappear." I take this to mean that there is a form of malaria which will not yield to quinin no matter how employed. The action of quinin upon certain types of malaria is very positive and undisputed. There are, however, phases or stages of what was doubtless originally a purely malarial affection, yet the precise nature of the pathologic phenomena soon becomes obscure and we deal with agencies supplementary to those originally and still present.

Exactly what constitutes this addition to the crescents already present in the blood, we have no present adequate answer. We know enough to know that the pathologic condition is not amenable to the therapeusis of quinin, no matter how much or by what avenue it reaches the blood.

$$
\text { Respectfully, J. Wellington Byers, M.D. }
$$

\section{Oxytuberculin}

Santa Clara, Cal, March 12, 1898. To the Editor:-My attention has been drawn to a letter in the Journal about oxytuberculin by Dr. E. H. Smith of Santa Clara, Cal. It is not my custom to reply to such letters, but a few facts will be at least interesting.

There are seven (or more) physicians in this county who have used oxytuberculis. How many of the cases treated by these physicians have been observed by Dr. Smith I am not able to state, nor do I know whether or not Dr. Hirschfelder has diagnosed all the cases of tuberculosis treated by these men. The letter states, "It is a very noticeable fact that all of the cases seem to be diagnosed by one individual, viz., Dr. Hirschfelder." For myself I shall reply, and will be glad to hear from the others. Dr. Hirschfelder never examined a case for me (nor the sputum) for at least three months after I had used treatment; nor has he ever diagnosed a single case for me. I have several times submitted the samples of sputum to him for satisfaction and for preservation of a slide by him. One case of mine to which Dr. Smith refers as "observed" by him, the letter states "That was a case of 'asthma,' and no positive evidence of tuberculosis at all. This case has been reported cured."

Now this case has never been reported "cured.".

Dr. Smith has never examined this patient, and yet hestates "These cases are not presented to an unbiased medical profession for diagnosis." What could be more biased than to say that a certain case was "asthma" and not "tuberculosis," without having made any examination. Let us see whether or not this was a case of " asthma ;' and, notice, that before oxytuberculin or Dr. Hirschfelder were known to me at all, this case was diagnosed "consumption" early in 1896. Dr. P. M. Lusson of San Jose, examined the patient and gave his diagnosis as "pulmonary tuberculosis in both lungs." I was not acquainted with the patient at that time. On Aug. 6, 1896, this patient presented herself at my office for examination. My notes taken at the time are as follows: Temperature 101.5 degrees; pulse 104 ; cough very annoying; losing flesh ; expectoration abundant; left lung affected to third rib; right lung to fourth rib; nocturnal paroxysms of asthma causing patient to smoke asthma powder from six to fifteen times a night ; weight about 103 pounds ; usual weight for five years 110 pounds; microscope shows abundant tubercle bacilli. Diagnosis: Pulmonary tuberculosis, complicated. Treatment: Outdoor life, generous diet, tonics, creosote carb., protonuclein, etc., with cough mixtures.

November 6 , gradual decline ; weight about 100 pounds ; no improvement.

November 16, tubercular pleurisy, severe; tubercular foci throughout both lungs.

Dr. I. N. Frasse of San Jose, called in consultation. Diagnosis according to written statement: "a clear case of phthisis." (He examined the sputum also.)

The doctor told the husband of the patient that in his opinion she would not live much longer than one week. He did not recommend any drugs, but agreed to use oxytuberculin or anything, as the case was far gone. After three months treatment, the patient did her own housework. In six months weighed 122 pounds, or twelve more than for four years.

The asthma has returned only two or three times in 15 months. and then only after a heavy meal, and the attack was completely stopped by one treatment of oxytuberculin, within fifteen minutes after administration. The patient feels well, sleeps 
ten hours daily uninterruptedly and does her own work. No medicines were used for six months during the treatment with oxytuberculin. Dr. Frasse has examined the patient twice since his first consultation at intervals of about three months, and writes me, "at my last examination some time ago I could still detect some bronchial breathing at the apex of the right lung, posteriorly, but otherwise the patient had made most excellent progress." Four other physicians examined this patient during the first four months of the treatment, each one unhesitatingly saying that it was a case of "tuberculosis."

Is it fair or "unbiased" to call this a case of "asthma?" Does "positive evidence" of tuberculosis only come from an examination by Dr. Smith and none other? Would you submit a case for an opinion to a man who will diagnose the case without an examination?

In every case that I have treated with oxytuberculin there is as much proof of tuberculosis and confirmatory evidence as in the above case, and I challenge proof that the tuberculosis did not exist in every case. Of four cases under my care in which oxytuberculin was used, two made marked improvement, one considerable improvement, one very slight improvement. With Koch's T. R., several cases have made some improvement. My own experience does not lead me to say that oxy tuberculin will cure a single case of tuberculosis, nor do I pretend to champion the remedy. Facts are better than statements. Until we find a remedy that will cure every case, it is better to wait for time to reveal the worth of every treatment. Where there are no contra-indications, why not use combined means, medicine, diet, exercise, hygiene, and any available specific treatment? The idea is not to prove the worth of any one remedy, but to cure the patient. Invariably, however, I explain to the patient that no guarantee of cure can be given. Yours respectfully,

D. A. Beattie, M.D.

\section{Advertising in the Secular Press.}

Tecumsen, Мich., March 10, 1898.

To the Editor:-In these days of push, of progress, of smokelese gunpowder, of climbing to the pinnacle of fame by every available means, is it not right, yea, is it not the only certain method by which a young and ambitious medical graduate can lift himself bodily into the aerie of success, by advertising his wares in the secular press where he locates, and informing his patrons through the press of his undoubted ability after the following manner?

Dr. Obediah Hayseed, assisted by Dr. Mossback and Dr. Falstaff of Rouge's Hollow, successfully removed a tumor from Mrs. George Gumbo. The patient is doing nicely. Is this not the proper method of becoming eminent with a single bound? Respectully yours, J. F. Jenkins, M.D.

\section{PUBLIC HEALTH.}

A New Source of Contagion,--The Méd. Moderne relates the case of a child with scarlet fever. As a new dress was required, the mother had a number sent. up from the stores and tried them on the child, returning all but the one she decided to buy.

The Favorable Effect of Hyglenic Measures on the Eyesight is emphasized by a report recently published detailing the results of the examination of the eyes of school children practiced in Munich two or three times a year for the last sixteen years. The average of vision is constantly rising.

Free Sanitaria for Nervous Affections.-Munich is soon to have an institution to receive male cases of functional neurosis, at a nominal sum, one mark a day. A minister, Ringseisen, has placed a couple of villas at the disposition of the committee in charge of the project, and money has been subscribed to build another. As soon as sufficient funds have been collected to maintain them, they will be put in operation, excluding alcoholics and epileptics. - Klin. Therap. Woch., January 30.

Health in Chicago.- The report for January gives the total deaths during the month as 1835 , or 1.13 per 1000 . The rate for the corresponding month in 1897 was 1.25 . Of these 1835 deaths, 390 were of persons under one year old, and 217 between one and five years. The chief causes were: Pneumonia, 248; nervous diseases, 226 ; consumption, 202 ; heart diseases, 124 ; bronchitis, 92 ; diphtheria and membranous croup, 68 ; cancer, 67 ; acute intestinal diseases, 79 ; typhoid fever, 29.

Health in Michigan. The report for February gives the diseases most prevalent during the month as rheumatism, influenza, neuralgia, bronchitis, tonsillitis, pneumonia, pleuritis, diarrhea and pulmonary consumption. Compared with the report for January, consumption was more prevalent, being reported at 117 places, while measles was reported at 85 places, scarlet fever at 68 , diphtheria at 60 , typhoid fever at 53, whooping cough at 27 , and smallpox at one place. Compared with the average for February for twelve years, whooping cough, intermittent fever, remittent fever, consumption, scarlet fever, diarrhea and pneumonia were less prevalent.

Sex and Population.-The London Post in the turbulent wake of the statistician gives some space to the disparity of the sexes, but wrongly credits Egypt as being the only country of the world where the men exceed the women. The avowed number foots up as high as 160,000. Let us dip into the question somewhat. The alleged preponderance of men in the United States is held to be 1,513,510, and in A ustralia the comparison suffers still more. But by the last Italian census, certainly the most accurate of all, the excess of male over female inhabitants is in the proportion of 50.20 to 49.80 . In Greece the percentage of male inhabitants is higher even than it is in Italy, and so it is, too, in Servia and Roumania. In all the South American countries, with the exception of Chile and Venezuela, men outnumber the women, and this is particularly the case in Brazil and in the Argentine Republic. In England's South African Colonies, in India, and in Canada, as well as in Egypt, the number of male inhabitants exceeds the number of female inhabitants. Egypt's claim to any particular prominence in this matter is based on a very slender foundation at best. By the census previous to the last one it was shown that the total number of male inhabitants was 3,402,000 and the number of female inhabitants was $3,416,000$. In a population, therefore, of nearly $7,000,000$ the excess of female inhabitants at that time was 14,000 , and if since then the scale has been turned slightly and now shows a small preponderence of men, there is certainly nothing in it which particularly calls for any great demonstration of surprise. The only commentary after all seems to be that the masculine element is reasonably content with an unembarrassed struggle for existence.

State regulations of Tuberculosis.-Dr. J. M. Withrow, Health Officer of Cincinnati, in the Ohio Sanitary Bulletin for February, says :

"Fourteen States have bovine laws and regulations, and issued circulars for public instruction with reference to tuberculosis in man, i. e., California, Colorado, Connecticut, Iowa, Maine, Massachusetts, Michigan, New Jersey, New Hampshire, New York, Pennsylvania, Rhode Island, Virginia and Wisconsin. Two States have bovine laws, but do nothing toward stopping the spread of tuberculosis in man, i. e., Minnesota and South Dakota. Tennessee has bovine laws, but can not enforce them for lack of funds, and the Health Board has only issued circulars upon the prevention of tuberculosis in man and beast. The District of Columbia and Oklahoma have a law prohibiting the sale of tuberculous milk, but nothing concerning the disease in man and cattle. Delaware, Indiana, Kentucky, Louisiana, New Mexico, Ohio, Texas and West 